Filol. linguist. port., n. 14(2), p.309-341, 2012.

\title{
Notas sobre a amizade: um estudo acerca do envolvimento interacional em cartas pessoais
}

\author{
Marise Adriana Mamede Galvão ${ }^{1}$ \\ Luiz Antônio da Silva ${ }^{2}$
}

\begin{abstract}
Resumo: Este trabalho tem como foco principal a descrição e análise de aspectos da interação verbal em cartas pessoais, tendo como corpus de investigação a correspondência partilhada entre Mário de Andrade e Luís da Câmara Cascudo. Parte-se de uma discussão acerca de gênero textual, enquanto entidade empírica, seguida de uma reflexão que centra a atenção na carta pessoal, como gênero que se concretiza na interação humana. Nesse âmbito, entre os vários objetivos estabelecidos para a escritura de cartas, salientam-se os que possibilitam aos interlocutores manterem relações de amizade, mesmo a distância, mediante o envolvimento que se instaura entre eles. Assim, tendo-se como base postulados interacionais, esta pesquisa propõe uma análise interpretativa e indutiva de fenômenos linguísticos e discursivos evidenciados nas cartas pessoais selecionadas.
\end{abstract}

Palavras-chave: cartas pessoais, interação verbal, envolvimento.

\section{INTRODUÇÃO}

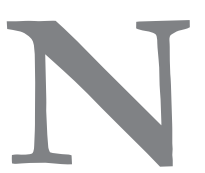

este estudo, privilegiamos aspectos da interação verbal evidenciados em cartas "trocadas" por dois autores brasileiros: Mário de Andrade e Câmara Cascudo. Nesta proposta, objetivamos descrever, analisar e interpretar ocorrências linguísticas e textuais/discursivas compreendidas como aspectos da relação de amizade, construída no envolvimento interpessoal, na escritura das cartas. Embora reconheçamos que o sentimento (Rezende, 2002) da amizade perpassa a maioria das 159 cartas (reunidas por Marcos Antônio de Morais, 2010), compartilhadas pelos dois escritores, selecionamos deste corpus 20 exemplares, nos

Universidade Federal do Rio Grande do Norte. E-mail: marisemamede@gmail.com

$2 \quad$ Universidade de São Paulo. E-mail: luizs@usp.br 
quais encontramos referências ao "amigo", "caro amigo", "prezado amigo", entre outras, como evidência de envolvimento interacional estabelecido na confiança, na lealdade, na reciprocidade, no afeto.

Faz parte de nosso projeto discutir sobre alguns aspectos da interação verbal que permeiam as cartas pessoais, assim, centramos atenção, desta feita, numa forma de manifestação da sociabilidade dos indivíduos, em um gênero que propicia a proximidade entre pessoas que se encontram distantes no tempo e no espaço. Não obstante, esses indivíduos podem "conversar", estabelecendo um lugar de interesses mútuos em trocas comunicativas.

Elegemos como metodologia de trabalho uma abordagem qualitativa e indutiva dos dados, a partir de evidências características de um gênero textual/ discursivo e da interação que se instaura entre os interlocutores na escritura e leitura das cartas. Nessa direção, adotamos discussões teóricas advindas de posturas sociointeracionais, entre estas as de Bahktin, 2000; Marcuschi, 2008; Bazerman, 2005; Silva, 1997; Silva, 2002. Além disso, buscamos uma visão mais ampla da questão do envolvimento e da amizade, em abordagens filosóficas e antropológicas, a fim de deixar clara a compreensão acerca do que investigamos.

Este trabalho, para tanto, se divide em seções: de introdução, que deixa patente a direção que seguimos; de discussão teórica, a fim de revelar as noções e conceitos que norteiam a reflexão; de análise, cujo objetivo é descrever e interpretar os dados de investigação; de conclusões, que revelam as contribuições da proposta.

\section{CONSIDERAÇÕES TEÓRICAS}

\subsection{Gênero}

Pretendemos, inicialmente, tecer algumas considerações, embora breves, acerca da noção de gênero, tendo em vista que este estudo tem a carta pessoal, ou seja, um determinado gênero textual/discursivo como objeto de investigação. Para tanto, temos como ponto de partida o postulado bakhtiniano, utilizado pela grande maioria dos autores que discute a questão de gênero: "A utilização da língua efetua-se em forma de enunciados (orais e escritos), concretos e únicos, que ema- 
nam dos integrantes duma ou doutra esfera da atividade bumana" (BAKHTIN, 2000: 279). Esses enunciados refletem as condições e finalidades de cada uma das esferas, evidenciadas por meio do conteúdo temático, da seleção dos recursos linguísticos e pela construção composicional.

Nessa direção, Marcuschi (2008) revela que a posição teórica de Bakhtin conduz ao postulado de que não é possível abordar gênero do discurso fora de sua realidade social e da relação com as atividades humanas. Para Marcuschi, (2008:154), a noção de gênero é ligada ao envolvimento social, conforme menciona em uma das discussões, ao defender a seguinte tese: “[...] é impossivel não se comunicar verbalmente por algum gênero, assim como é impossivel não se comunicar verbalmente por algum texto." Essa postura do autor significa que dominamos formas de realizar linguisticamente determinados objetivos nas várias situações sociais por nós experimentadas. Assim, compreendemos como devemos proceder para produzir um relatório de pesquisa, um ofício para o chefe, uma lista de compra, uma carta, ou mesmo tantos outros gêneros que surgiram ou se transformaram com os avanços da tecnologia.

$\mathrm{Na}$ visão de Bazerman (2005), percebemos quando um texto funciona bem em uma determinada situação e, quando nos encontramos em outra semelhante, seguimos padrões comunicativos que são reconhecidos facilmente pelas outras pessoas. Essas "formas de comunicação reconheciveis e auto-reforçadoras emergem como gêneros" (Bazerman, 2005: 29). Além disso, o autor chama a atenção para as mudanças que ocorrem no conhecimento ao longo do tempo, para dizer que os gêneros mudam, tendo em vista que são partes de processos de atividades emergentes organizadas socialmente pelas pessoas, na partilha de significados, tendo em vista seus propósitos práticos.

Nessa direção, ressaltamos a postura teórica adotada por Marcuschi (2008: 155), compreendendo que textos são materializados em situações comunicativas e que gêneros textuais "são os textos que encontramos em nossa vida diária e que apresentam padrões sociocomunicativos característicos definidos por composições funcionais, objetivos enunciativos e estilos concretamente realizados [...]".

Dessa forma, o gênero é uma entidade empírica usada em situação de comunicação, assim, as pessoas interagem em eventos concretos, reais, assumindo papéis comunicativos e posições sociais, conforme assegura Silva 
(2002), ao se reportar à noção de gênero e ao funcionamento de textos em eventos comunicativos.

A partir dessas observações, na próxima seção tecemos considerações acerca da carta pessoal, como uma forma textual com certa estabilidade, escrita, situada histórica e socialmente, definida por uma composição, objetivo enunciativo e estilo.

\subsection{Gênero carta pessoal}

A carta é um dos gêneros usados em nossas práticas cotidianas, com objetivos dos mais variados, entre esses, relatar ocorrências da vida diária, o que torna possível às pessoas manterem relações de amizade. Assim, trata-se de um gênero concretizado na interlocução humana, fato que condiciona nossas escolhas do ponto de vista do léxico, do grau de formalidade e da natureza dos temas. Alinhamo-nos, portanto, ao pensamento de Marcuschi (2008: 156), para defender que gêneros são concebidos como "formas culturais e cognitivas de ação social corporificadas de modo particular na linguagem".

Tomando uma direção mais específica, dentro dos nossos propósitos, a discussão de Silva (1997) nos esclarece algumas questões necessárias quando se pesquisa aspectos de cartas pessoais. A autora, de acordo com o que citamos a seguir, expressa seu ponto de vista em relação à carta, estabelecendo posteriormente uma classificação de cartas pessoais:

de fato o rótulo carta é abrangente e pouco esclarecedor: excetuando-se o formato externo - cabeçalho, data, assinatura - e algumas expressões formulaicas freqüentes em suas seções iniciais e finais, o corpo da carta permite qualquer tipo de comunicação: desde as vantagens de um determinado cartão de crédito até informações sobre o condomínio, passando pelas esperadas novidades do amigo que mora no exterior. Todas são cartas, mas não devemos colocá-la na mesma categoria (SILVA, 1997: 121).

A partir dessa reflexão, Silva (1997) ressalta que em uma classificação de cartas, tendo em vista o propósito comunicativo, reconhecemos a intenção de quem escreve, de modo que as cartas pessoais cumprem propósitos, entre estes, convites, agradecimentos, informações, desculpas, conselhos. Normal- 
mente, há uma sobreposição de propósitos, entre eles o de informar sobre a vida cotidiana, ou agradecer por um presente, ou mesmo reclamar da falta de notícias, sendo que algum pode se destacar como predominante. No entanto, na carta pessoal, como destaca a autora, a interação, o envolvimento entre os interlocutores é o mais importante. Assim, quem escreve usa estratégias que possibilitam ao que lê a impressão de que estão em uma interação face a face.

No trabalho intitulado Cartas da administração privada e cartas particulares: estudo da organização discursiva, Brandão, Andrade e Aquino (2009: 707) focalizam a configuração do gênero carta e explicitam que nestas podemos observar "maior ou menor grau de cumplicidade, de afetividade, de expressividade entre outros". Isso revela as categorias pragmático-discursivas do gênero carta, com base no quadro elaborado por Simões ${ }^{3}$ (2007: 182), a partir do qual as autoras fazem uma proposta, situando as cartas conforme: grau de exposição (pública - administrativa, jornalística; privada - administrativa, familiar, entre amigos), grau de centração tópica (centração, maior centração, menor centração); grau de planejamento e registro textual (planejado, relativamente planejado, relativamente não-planejado, podendo ser controlado, semicontrolado ou livre); grau de relação de poder e cumplicidade (descendente, horizontal, ascendente, revelando distância ou proximidade); dimensões da ação discursiva (sequências: de abertura, narrativa, descritiva, explicativa, argumentativa, injuntiva, dialogal, de fechamento).

Quanto à configuração, as cartas comportam elementos fixos, contextualizadores, a saber: local de procedência, data, assinatura, e um elemento alternativo, o post scriptum, identificado como PS. Também, as autoras (p. 707) sistematizam em um quadro as seções ${ }^{4}$ da carta: local e data, endereçamento, abertura, desenvolvimento (sequências), fechamento, assinatura e post scriptum. Sabemos, por experiência com as práticas nesse gênero, que, nem sempre, cartas apresentam todas as seções. Justificamos esse fato, considerando que os gêneros são mais ou menos estáveis, tendo em vista que se concretizam em situações

3 No trabalho de 2009: 487, Simões e Kewitz se referem às categorias discursivo-pragmáticas para a língua escrita, propostas em Simões e Kewitz (2005), com base na sugestão de Henne e Rehbock (1982) e Allwood (1976), para a análise da língua falada, a saber: grau de publicidade, grau de simetria entre os escritores, fixidez temática, dimensões da ação discursiva, grau de planejamento do texto (registro/níveis de fala).

4 O termo seção aqui designa as partes de cartas. 
mais, ou menos simétricas, revelando graus de maior ou menor proximidade entre os interlocutores e, consequentemente, textos com graus diferenciados de registro e planejamento. Por exemplo, se produzimos um texto acadêmico, é difícil aceitá-lo sem uma introdução, mas é possível uma carta pessoal sem abertura, ou sem o local de procedência explicitado.

Tendo em vista o objetivo que estabelecemos, ao pensarmos nessas categorias pragmático-discursivas do gênero carta, compreendemos que as relações de poder e cumplicidade, deixam visíveis os graus de distância e de proximidade entre as pessoas, além de deixar claro se as relações na interação são ascendente, horizontal ou descendente. Assim, podemos identificar as marcas linguístico-discursivas da hierarquia entre os interlocutores, o envolvimento entre eles, por meio das formulações realizadas nas idas e vindas desses textos concretizados com diferentes objetivos.

Ressaltamos, nesse sentido, a reflexão de Silva (2002), cujo objeto de análise são as cartas pessoais. Para essa pesquisadora (2002: 22), "o gênero textual figura nas relações interpessoais como um dos elementos-chave para a construção das interações verbais, viabilizando, assim, a efetivação dos processos de socialização e sociabilidade dos individuos." A partir daí, a autora (p. 60) ressalta que, passados alguns anos em que as cartas emergiram, nos meados do século XVII, na Inglaterra, reconhece-se que "os textos atualizadores desse gênero epistolar ainda continuam fiéis à finalidade social que o engendrou: assegurar ou proporcionar um convívio, à distância, com aqueles que amam ou têm um estreito relacionamento social [...]”. Nessa direção, os gêneros textuais são construídos na interlocução, portanto, as pessoas interagem e assumem papéis comunicativos e revelam posições sociais durante o seu transcurso.

Ao refletir sobre as práticas comunicativas, Silva (2002) salienta que estas incluem as atividades sociais em que a linguagem é produzida. Ressalta, também, que as práticas comunicativas de um gênero textual expressam como as pessoas agem em determinado evento, do ponto de vista linguístico, discursivo, cognitivo e social. Além disso, essas práticas evidenciam as demandas dos contextos social, histórico e cultural em que estão inseridas. Faz-se necessário, assim, refletir sobre essa posição da autora, a fim de discutir e compreender o sentido da interação na troca de cartas pessoais.

\subsection{Interação}


Silva (2002) chama atenção para os conceitos de interação, conforme alguns estudos que embasaram sua investigação, entre eles os de Hymes (1972), Goffman (1974) e Gumperz e Hymes (1974). Silva (2002) reconhece que o conceito de interação é utilizado por esses autores para definir eventos realizados face a face, com a participação conjunta de interlocutores, a partir da utilização de estratégias textuais, linguísticas, cognitivas e interativas. No entanto, ela salienta que os autores citados tinham, em seu campo de visão, a noção mais ampla de interação, inscrita em qualquer atividade mediada pelo discurso, constituindo um quadro regido por regras pragmáticas, adequadas a uma determinada situação. Assim, ressalta que

a dimensão interativa envolve e caracteriza toda e qualquer produção discursiva, na qual se pressupõe a (inter)ação dos participantes sobre (e entre) si mesmos, sobre os saberes partilhados que abrangem os conhecimentos ditos enciclopédicos, os relativos ao gênero textual atualizado, as representações da situação comunicativa em que estão engajados, o(s) assunto(s) em questão (SILVA, 2002: 23).

Estabelecida essa noção, reconhecemos que a interação é definida com base em trocas comunicativas entre as pessoas, a partir de um foco comum estabelecido, além de se efetivar quando as pessoas assumem papéis definidos socialmente, considerando a situação da qual participam. Por esse ângulo, tomamos, também, o termo interação no sentido atribuído por outros pesquisadores, entre estes Marcuschi (1998), apud Fávero et al (2010: 91-92), que discute acerca dessa noção afirmando:

Sendo o ser humano um ser social, todas as suas ações têm a ver com este aspecto crucial de seu comportamento diário. Assim, tendo o ser humano que agir na relação com seus semelhantes de maneira ordenada, deve sempre interagir, ou seja, atuar na perspectiva de uma ação coordenada. Isto faz com que as ações humanas construam-se, no geral, como interações, na maioria das vezes mediadas pelo uso da língua que por sua vez facilita a interação intersubjetiva (Marcuschi, 1998).

Alinhamo-nos ao pensamento do autor, compreendendo que toda interação entre seres humanos é social, constituindo-se de forma ordenada e organizada, por meio da qual as pessoas deixam transparecer intenções, cons- 
troem sentidos e partilham realidades sociais. Para Eggins e Slade (1997: 6), "interagir não é apenas um processo mecânico de tomar turnos ao produzir sons e palavras. Interagir é uma atividade semântica, um processo de produðir significados". Essa definição assume o sentido de partilhamento de significados, na realização de tarefas pragmáticas, desde as mais simples até as mais complexas, com objetivos vários, entre estes informar, solicitar, reivindicar, enfim, participar de atividades práticas que envolvem o outro. Nessa visão, a necessidade de estabelecermos com as outras pessoas quem somos em determinada relação evidencia como pensamos acerca de nossa realidade, que motivações nos levam a partilhar interesses, sentimentos, pontos de vista, emoções, etc.

Também, a discussão de Morato (2004) sobre interação ressalta o caráter polissêmico do termo e salienta a idéia de reciprocidade e reflexividade de comportamentos das pessoas em diferentes contextos e práticas sociais. A autora (2004: 323), a propósito, esclarece que "as abordagens interacionistas no campo psicolinguistico consideram a linguagem uma ação compartilhada que percorre um duplo percurso na relação entre sujeito e realidade: intercognitivo (sujeito/mundo) e intracognitivo (linguagem e outros processos sociais)". Nessa discussão, a interação é base da construção do conhecimento e da dupla natureza da linguagem, a saber, cognitiva e social. A reflexão da autora nos possibilita compreender que escrever cartas para solicitar, informar, relatar acontecimentos, dizer sobre o bem querer, reclamar - entre tantas funções - é uma forma de interação, envolvendo uma prática das mais antigas, milenares.

Assumimos, assim, que a troca de cartas pessoais se trata de interação entre participantes, distanciados no tempo e espaço, mas que constroem sentidos nessa escritura, a partir de um campo comum de mútua compreensão, sendo necessário que partilhem conhecimentos, crenças, pontos de vista, entre outras questões. Nessa direção, para que possamos tratar da questão definida como objetivo deste trabalho, discutimos acerca da relação que as pessoas expressam não somente em relação um ao outro, mas em relação ao mundo.

No que se refere ao estabelecimento de relações sociais por meio de interações, Silva (2002: 26) faz referências aos estudos de Vion (1992), para quem "a nossa história interacional é constituída pela totalidade das interações das quais efetivamente participamos [..]" tanto no papel de produtores, 
quanto no papel de ouvintes, leitores de uma variedade de textos em gêneros diferenciados em situações sociais também diferenciadas.

Assim sendo, centrando no ponto de vista de Silva (2002) acerca das relações estabelecidas na carta pessoal, destacamos que estas cumprem necessidades comunicativas da sociedade, no espaço privado. Essas necessidades ligam-se aos objetivos de construção, preservação e consolidação de relações de amizade, a partir do intercâmbio de pessoas em lugares distintos. Sobre essa questão, Brandão et al (2009: 705) mencionam que as cartas se popularizaram, tendo em vista a necessidade das pessoas com relação aos contatos com familiares e amigos distantes. Com isso, criava-se uma tradição discursiva e a carta "passa a exercer a função de correspondência privada entre amigos e parentes [... P’.

Ressaltamos que, na escritura das cartas, as pessoas assumem papéis circunstanciais de remetente e destinatário imbricados nessa prática. Nessa ótica, convém discutir sobre a questão, a partir das considerações de Kerbrat-Orecchioni (2006). Essa pesquisadora propõe uma tipologia de interações, partindo dos seguintes critérios: um quadro espácio-temporal, que define a natureza do lugar; o número e a natureza dos participantes, com relação aos estatutos e respectivos papéis, considerando o contrato que assegura a manutenção conjunta destes; qual o objetivo da interação, além do estilo predominante e do grau de formalidade que caracteriza o evento. Fazemos um diálogo entre os propósitos dessa autora, as considerações de Brandão et al (2009) e a proposta de Silva (2002: 80), que parte da hipótese de que a carta pessoal é uma "produção de linguagem, socialmente situada, que engendra uma forma de interação particular". Isso implica a observação de formas de interação na sociedade, incluindo-se as relações interpessoais de indivíduos em situações variadas.

Nesse sentido, Silva (2002) salienta que na atualização de toda atividade discursiva pressupõe-se a existência de um locutor, um destinatário, de um quadro situado no tempo e no espaço, conforme Kerbrat-Orecchioni (2006), em uma esfera privada ou pública de comunicação, com vistas a um determinado objetivo. A pesquisadora reflete sobre as considerações de Biber (1988), o qual se pauta nos elementos da situação comunicativa a partir de Hymes (1974), propondo os seguintes elementos: participantes, relações entre estes, contexto físico, tópico ou tema, propósito comunicativo, avaliação social, relação dos participantes com o texto e suporte (canal). Silva (2002), dado o interesse de 
seus estudos, propõe a reunião de alguns elementos no quadro das interações: ao componente participante, integra os papéis comunicativos e a posição social em jogo no evento. Isso implica considerar a relação social que se estabelece, o status de participação, o relacionamento interpessoal, além da naturez̧a dos conbecimentos partilhados (de mundo, gênero, normas sociais e comunicativas) e a avaliação que as pessoas realizam acerca do evento.

Nessa visão, as cartas pessoais deixam transparecer as realidades dos interactantes, qual o grau de afinidade e intimidade entre eles, se são amigos, pai, mãe, filho, entre outros. Assim, do ponto de vista linguístico-discursivo, fica patente os lugares de onde as pessoas falam e a forma como constroem a interação nesse gênero específico.

Nossa pretensão maior, portanto, está centrada na relação entre amigos que é construída/mantida ao longo das cartas que são partilhadas ou trocadas por Câmara Cascudo e Mário de Andrade. Assim, buscamos observar como os dois escritores, a partir do envolvimento que estabelecem na convivência, cultivam essas relações de afeto e que marcas dessa amizade são patentes linguística e discursivamente. Assim, tendo por base as noções de gênero textual e de interação concretizadas em correspondências, centramos atenção no envolvimento interpessoal enquanto evidência linguística e textual/discursiva.

\subsection{Envolvimento interacional}

Para falar de envolvimento interacional, explicitamos a forma como atrelamos esse aspecto ao que já definimos teoricamente até o presente momento. $\mathrm{Na}$ discussão, ressaltamos que carta pessoal é um gênero textual constituído na esfera privada. Por este prisma, as pessoas estabelecem relações que podem ser calcadas na sinceridade, na confiança, na sensibilidade, em uma prática comunicativa específica. Estes elementos marcam o tom da interação, considerando que um interlocutor busca a compreensão do outro, que provavelmente age de forma semelhante, já que se trata de um caminho de mão dupla, construído por amigos em lugares distintos e em tempos também diferentes.

Sabemos que, nem sempre, cartas pessoais refletem a amizade, a confiança e o bem querer que podem marcar a interação entre as pessoas que se utilizam desse espaço possibilitado na escritura, já que os gêneros se prestam a diferentes objetivos não só ao longo do tempo, mas a cada momento em 
particular. Porém, o encaminhamento dado a essa reflexão, se pauta no que vislumbramos na grande maioria das cartas que constituem o corpus de análise deste estudo, a amizade construída, mantida e consolidada ao longo de interações efetivamente estabelecidas.

Nosso objetivo, neste trabalho, pauta-se em questões linguísticas e textuais/discursivas, no entanto, buscamos em outras teorias compreender o significado mais amplo da amizade nas relações sociais, em práticas comunicativas. O ensaio acerca da antropologia das emoções, de Rezende (2002: 69), nos fornece uma definição de amizade, numa perspectiva geral, como "uma relação efetiva e voluntária, que envolve práticas de sociabilidade, trocas intimas e ajuda mútua, e necessita de algum grau de equivalência ou igualdade entre amigos (Allan 1989; Paine 1974; Suttles 1970)". Porém, a autora ressalta que, em trabalhos mais atuais, os significados da amizade se mostram entrelaçados com uma forma de pensar a pessoa e sua relação com os outros, colocando em foco também a localização desta na esfera privada.

Nessa visão, Rezende (2002) analisou o discurso e a prática da amizade, tendo se utilizado de entrevistas e de conversas informais em bares, cinemas, festas, jantares, enfim, em uma diversidade de situações sociais. A discussão dessa autora (2002:74) elege uma abordagem contextual em que os conceitos de emoção devem ser compreendidos "como elementos de práticas ideológicas locais que envolvem negociações sobre o significado de eventos, sobre direitos e moralidade, sobre o controle dos recursos, em suma, sobre todas as esferas da vida social'. Nessa proposta, a autora enfatiza que as emoções são uma espécie de lugar de negociação das relações sociais entre as pessoas, de forma que o discurso das emoções é analisado no conjunto de atos pragmáticos e performances comunicativas, considerando quem, para quem, quando e quais os propósitos em determinado contexto. Assim, na análise de Rezende, a amizade é objeto de negociação nas relações entre amigos situados socialmente em termos de raça, gênero e classe. A autora menciona que a noção de amizade é perpassada por negociações de significado e poder, numa dinâmica entre o desejo que temos de nos relacionar com os outros e de mantermos a privacidade, que marca a vida moderna. Há um sentido de amizade com base na construção de interesses comuns, no senso de humor, na confiança mantida na relação desde o início. Além disso, a autora ressalta que os dados de sua pesquisa revelaram que relações de amizade também colocam em cena laços de identidade e de pertencimento em locais (cidades) 
onde imperam as mudanças e o anonimato das pessoas. Nas conclusões de Rezende (2002: 85-86), "o idioma emotivo veiculado pela amizade fala, portanto, da relação entre amigos, e, ao mesmo tempo, de sua inserção mais ampla em um determinado contexto sociocultural'.

Numa visão filosófica, Oliveira (2009: 129) nos diz que a base da amizade está no grau de confiança depositado no outro, a quem instituímos como amigo para o exercício da reciprocidade, da troca, no âmbito da vida social. Esse autor revela o caráter ativo da amizade, para salientar que o prazer de acolher os amigos e de sentir-se feliz com seus progressos, mesmo que à distância, são evidências em textos que remontam longo tempo, como nas cartas de Sêneca a Lucílio (1991), uma versão traduzida do Inglês (1989), com texto original cujo título é: Ad Lucilium epistulae morales.

Os comentários aqui realizados nos possibilitam estabelecer uma compreensão acerca da amizade, de como os interlocutores, em um determinado gênero, na partilha de cartas pessoais, vão criando laços afetivos. Prevalece a ideia de que a possibilidade de estar com o outro, de criar um espaço comum calcado na reciprocidade e na confiança estabelecida no parceiro na escritura das cartas pessoais pode ser vista por meio do que é dito e da forma como é dito. Dessa forma, compreendemos a questão, como evidência do envolvimento no processo da escritura concretizado por estratégias linguísticas e textuais/ discursivas passíveis de análise.

Para a efetivação desta pesquisa, refletimos, também, sobre a proposta situada em um dos capítulos do livro de Eggins e Slade (1997), sob o título "Analisando a conversação casual", na perspectiva funcionalista. Esse trabalho traz uma discussão importante para nossa investigação, ao abordar a semântica da conversação casual. Essas autoras mencionam que,

ao rever os recursos disponíveis aos falantes por meio dos dois sistemas semântico de julgamento e envolvimento, estamos sugerindo que a expressão de atitude na fala casual é um artifício importante para construir e sinalizar graus de solidariedade e intimidade em relacionamentos (Eggins; Slade, 1997: 116).

Conforme as autoras, não apenas o envolvimento, mas também a avaliação e o humor constituem as três áreas principais da semântica interpessoal. 
A avaliação tem a ver com a questão atitudinal na conversação e inclui as respostas emocionais, a avaliação social, entre outras; o humor tem a ver com a criação de laços de solidariedade; já o envolvimento faz referência ao mundo interpessoal compartilhado pelos interactantes na conversação. Ao analisarem conversações entre colegas em locais de trabalho, as autoras mencionam que os resultados mostram um quadro de papéis e relações sociais evidenciados na fala, no sentido de laços coesivos construídos com base na vida diária.

Quanto aos recursos linguísticos, no estudo de Eggins e Slade (1997), utilizados pelos participantes da conversação, na direção de estabelecer um alinhamento coerente com relação a um grupo, inclui: vocabulário indicativo de atitude de apreciação e avaliação do comportamento do outro; palavras com significados reconhecidos internamente por um grupo (in-group words); gírias, blasfêmias sugestivas de coesão grupal; termos abreviados que indicam graus de intimidade.

No sentido do envolvimento interpessoal, os dados interpretados pelas pesquisadoras evidenciam o mundo compartilhado pelos participantes, por meio do uso de vocativos, gírias, linguagem específica (anti-language) e expressões de tabu. Há, nesse sentido, uma semântica do envolvimento, na construção da intimidade e afiliação dentro de um grupo específico, socialmente falando. Por meio de vocativos, as pessoas objetivam chamar atenção do outro, além da possibilidade de exercerem um controle efetivo na interação. As formas de vocativo nos dados das autoras incluem: uso de títulos e sobrenomes, primeiros nomes, formas completas modificadas, apelidos, termos de agrado ou de abuso. O uso de léxico técnico, ou especializado, também indica um campo comum compartilhado por pessoas de um determinado meio ambiente e de um grupo social; além disso, o uso de xingamentos e palavrões revela a casualidade ou formalidade da conversa. Já as gírias ou "anti-linguagem” sugerem a construção de realidade alternativa, como, por exemplo, o vocabulário em forma de código que pode ser usado por criminosos e prisioneiros em determinadas situações.

Outra dimensão do envolvimento interpessoal é vislumbrada na proposta de Tannen (2007), tendo como ponto de partida as considerações de Gumperz (1982) acerca do envolvimento conversacional, compreendido como base para toda compreensão linguiística. Gumperz (1982, p. 1) apud Tannen (2007: 25) revela que "compreender pressupõe envolvimento conversacional" e que "uma teoria geral 
de estratégias de discurso deve, portanto, começar especificando o conbecimento linguístico e sociocultural que precisa ser compartilhado se o envolvimento conversacional épara ser mantido [...]”. Tannen salienta que, para Gumperz, o envolvimento na interação se trata de inferir em níveis global e local sobre o que é a interação e acerca dos enunciados, ou seja, sobre o evento e o que se diz durante o transcurso deste.

Tannen também reflete sobre os trabalhos de Chafe $(1982,1984,1985)$ para deixar claro como ela compreende o sentido do termo, tendo como base a interação conversacional. Segundo Tannen (2007: 27), o sentido que Chafe atribui para envolvimento "descreve um estado interno, mais psicológico, que se mostra em fenômenos linguísticos observáveis”. Nessa perspectiva, a pesquisadora explicita que seu pensamento é mais próximo ao de Chafe, já que, em sua concepção, envolvimento é "uma conexão interna, mesmo emocional, que os individuos sentem, que os vinculam às outras pessoas, como também a lugares, coisas, atividades, ideias, memórias e palavras." Porém, enfatiza que, como Gumperz, observa a realização do envolvimento na interação.

Tannen (2007) postula, nesse sentido, que envolvimento não é apenas a alternância de duas ou mais pessoas na conversação, mas a incorporação, por cada uma, de traços e de elementos da fala do outro, ou seja, uma produção conjunta, colaborativa. Nessa perspectiva, há a criação de uma experiência emocional para a compreensão do texto e conexão entre os participantes.

As estratégias de envolvimento identificadas por essa autora fazem parte de ocorrências no discurso literário e no discurso conversacional, constituindo evidências relativas à identificação das pessoas por meio dos padrões de sentidos e por meio dos sons. A autora elenca as estratégias com base no som e com base no significado, sendo as primeiras: 1. ritmo; 2. padrões baseados na repetição e variação - de fonemas, morfemas, palavras, colocação de palavras e sequências mais longas no discurso; 3. figuras de estilo do discurso (entre elas as figuras de repetição). As estratégias baseadas no significado, conforme explicita Taneen são: 1. a "indirectness" (forma indireta); 2. a elipse; 3. os tropos; 4. o diálogo; 5. a imagem e detalhes, e 6. a narrativa.

Muitas dessas estratégias são observadas tanto em textos orais quanto escritos, de acordo com Tannen, de forma que em trabalho publicado em (1985), o qual passamos a focalizar, essa autora fala acerca do relativo foco no envolvimento pessoal e relativo foco no conteúdo ou na informação. Suas 
observações pontuam que alguns estudiosos caracterizam o discurso falado como altamente contextualizado e o discurso escrito como descontextualizado. Entretanto, na explicação, ela salienta que o foco relativo no envolvimento parece subjazer a compreensão tanto no discurso falado quanto no discurso escrito. Nessa direção, Tannen (1985) menciona que muito da conversação casual evidencia pouca informação partilhada entre os participantes, mas revela a ligação e envolvimento entre eles.

Ao analisar narrativas em inglês e grego, a partir de um determinado filme, Tannen (1985) observou que os gregos usavam uma abordagem de contar história (storytelling) e os americanos as estratégias de tarefa de memória. Os gregos tinham a tradição oral como base, focando assim no tema do filme, nos detalhes que contribuem para esse tema, no uso de explicações culturalmente familiares e personificação. Já os americanos se utilizavam da tradição literária, listagem de detalhes para correção, exatidão com relação ao tempo, crítica às habilidades produtoras do filme e análise do filme como um artefato. Assim, conforme o corpus analisado, o mesmo gênero revela estratégias diferentes na construção do discurso acerca de um tema semelhante por dois grupos de culturas diferentes.

Partindo dessas observações, Tannen (1985) traz duas hipóteses de aspectos relacionados ao foco relativo no envolvimento: da contextualização, segundo a qual o discurso falado é altamente contextualizado, diferentemente do escrito, descontextualizado. Nesse sentido, o contexto imediato é visível para os falantes, o que implica possibilidade de esclarecimentos, se necessários, no transcurso da interação. Já na escrita, o autor tem que prever quaisquer complicações, fornecendo ao leitor as informações necessárias acerca do contexto. No entanto, no dizer de Tannen (1985), tal visão é um exagero, haja vista que nenhum discurso é compreendido sem o conhecimento do contexto, considerando o gênero de sua produção.

O postulado de que, na interação face a face, é mais importante falar do que as informações e mensagens transmitidas, e que, na prosa expositiva (expository prose), a mensagem é relativamente mais importante, é questionado por Tannen (1985). Conforme ela compreende, é possível ter uma comunicação escrita com o mínimo de preocupação com o conteúdo, como por exemplo, em cartas pessoais, gênero em que é provável se escrever pela satisfação de manu- 
tenção do contato com o outro. Já em conferências, mesmo sendo produzidas na oralidade, o foco deve ser no conteúdo. Em redes televisivas e radiofônicas, em noticiários, o foco no envolvimento parece ser maior do que no conteúdo.

A segunda hipótese é atinente à coesão na fala e na escrita. Na fala, a coesão é realizada pelas pistas prosódicas e paralinguísticas, enquanto, no discurso escrito, a coesão deve ser lexicalizada; na fala, tudo é dito em um tom, em uma velocidade específica, observando-se alguma expressão na voz e na face do falante. Na escrita, a falta de canais orais favorece a utilização lexicalizada das relações entre ideias, além da atitude do autor em relação a estas.

Ao observar o foco no envolvimento na conversação, Tannen (1985) assume que isto requer uma significativa contribuição da audiência no suporte de informação contextual e no trabalho interpretativo. Nos dados analisados pela autora, nem todos os participantes utilizaram as mesmas estratégias de sinais linguísticos e paralinguísticos, entre estes, velocidade da fala, sobreposições, interrupções, humor, estruturas sintáticas, narrativas, etc. Alguns não compartilharam de forma semelhante o que os outros enunciaram. Assim, a autora identificou estilos com foco no envolvimento interpessoal e com foco no conteúdo informacional.

Alguns aspectos do efeito do foco no envolvimento que emergiram nas conversações, conforme essa autora, foram: mais histórias sobre experiências pessoais foram contadas, sendo que o ponto principal foi dramatizado e não lexicalizado; os participantes reagiram diferentemente quando os estilos de narrar divergiram de seus próprios estilos. Muitas vezes, eles questionaram “qual é o ponto?" e acharam que o evento era mais importante do que os sentimentos dos participantes, ou seja, preocupam-se com estratégias com foco maior na informação.

Tannen (1985: 137) sintetiza a reflexão acerca do envolvimento, ressaltando que não há tanta diferença entre a conversação espontânea e o típico gênero escrito, prosa expositiva. Além disso, observa que a prosa criativa (imaginativa) tem mais aspectos em comum com a conversação espontânea do que com a prosa expositiva.

Se a prosa expositiva é minimamente dependente do contexto imediato e maximamente dependente da lexicalização - ou seja, o escritor exige menos do leitor em termos de preenchimento dos referentes, informa- 
ção do contexto, premissas cruciais, relações coesivas e avaliação, então o discurso literário é também maximamente contextualizado, não no sentido de depender do contexto imediato, mas requerendo que o leitor (ou ouvinte) preencha máxima informação do contexto[...].

Isso significa que tanto a prosa literária quanto a conversação são dependentes do efeito do envolvimento interpessoal entre o falante/escritor e o ouvinte/leitor, ou seja, entre os envolvido na interação. Assim, tanto a escrita bem sucedida requer informações contextuais em relação à audiência, quanto esta se faz presente na interação face a face.

Chafe (1982) também discute acerca do envolvimento, discorrendo sobre aspectos linguísticos identificados na análise da relação entre fala e escrita. Segundo ele, em dados da fala, o envolvimento se manifesta por meio de algumas evidências linguísticas, entre estas, 1. referências à primeira pessoa (eu, nós, mim, nos); 2. referências à segunda pessoa ${ }^{5}$; 3. referências aos processos mentais do falante (eu penso, eu acho, etc); 4. monitoração do fluxo da informação (bem... eu, eu quero dizer..., você sabe...) ; 5. uso de partículas enfáticas que expressam entusiasmo (exatamente, realmente); 6. vagueza (algo como, uma espécie de, etc.) e 7. uso de citações diretas (ele disse 'Sally eu posso ter um de seus artigos?').

Em trabalho posterior, Chafe (1985), com intuito também de pesquisar as diferenças que distinguem fala e escrita, contrapõe o envolvimento dessa primeira modalidade ao afastamento presente na segunda, tendo em vista que os falantes encontram-se face a face, enquanto os escritores estão distantes de seus interlocutores. Nesse trabalho, o autor discute com relação a três tipos de envolvimento: do falante com ele próprio, o ego-envolvimento; do falante com o ouvinte - na dinâmica da interação e o envolvimento com o conteúdo, relacionado ao que está sendo falado.

Chafe, assim, relaciona ao ego-envolvimento não somente o uso dos pronomes (eu, mim, nós, meu, nossos), mas o uso de expressões reveladoras de referências aos processos mentais já mencionadas anteriormente (eu quero dizer, eu não sei, eu digo). Com relação ao envolvimento com o ouvinte, Chafe menciona: as formas de pronome de segunda pessoa, o endereçamento ao

5 O autor não encontrou muitas evidências nos dados analisados. 
outro pelo nome, respostas a perguntas, pedidos de confirmação, entre outros. Com relação ao interesse com o que está sendo comunicado, Chafe aponta as expressões que conotam exagero, o uso de exclamações, de vocabulário expressivo, de citações diretas, uso do presente histórico, entre outros.

Refletindo acerca das considerações feitas por Tannen $(1985,2007)$ e por Chafe $(1982,1985)$, observamos que há aspectos diferentes nos critérios que eles selecionam, tendo em vista que, para Tannen, a maior preocupação com o conteúdo pode ocorrer tanto em dados da interação face a face quanto em dados escritos. Para Chafe, que compreende esse tipo de envolvimento, sendo explicitado por meio de recursos linguísticos específicos, o envolvimento com o conteúdo ocorre nos dados de sua pesquisa em maior percentual em corpora da língua falada.

\section{ANÁLISE DOS DADOS}

\subsection{Configuração das cartas de Mário de Andrade e Câmara Cascudo}

Um aspecto inicialmente discutido faz referências à configuração genérica das cartas que constituem o corpus de investigação desta pesquisa. Nesse sentido, as cartas partilhadas pelos dois escritores apresentam, normalmente, características comuns ao que foi posto teoricamente. Esses interlocutores, situados em espaços diferentes, em tempos também diferentes, trocam correspondências com objetivos diversos, às vezes sobrepostos, entre estes, para comentar acerca de questões da cultura e literatura brasileiras; para agradecer por textos recebidos, como se observa no exemplo 1; para reclamar da falta de notícias de um dos parceiros, conforme identificamos no exemplo 2; para compartilhar impressões sobre lugares e pessoas, de acordo com o exemplo 3.

\section{Exemplo 1}

Carta de Mário de Andrade a Luis da Câmara Cascudo (14/08/1924: 33)

Você há-de permitir à minha modéstia que confesse a alegria que me deu o seu artigo. Muito obrigado. 


\section{Exemplo 2}

Carta de Câmara Cascudo a Mário de Andrade (19/05/1925: 40-41)Sua carta de $1^{\circ}$ de maio surpreendeu-me. Que é isto? Escrevi duas cartas. Silêncio fero e mau. Silêncio de cemitério. Amuei. Recebi, li, treli e quase decoro a Escrava que não é Isaura.

\section{Exemplo 3}

Carta de Mário de Andrade a Cascudo (4/09/1925: 60-62)

[...]. Estou no meio de vaqueiros e cantadores. Não há luz elétrica. A coisa que me lembra, e detestavelmente, o progresso, é meu Ford que está parado debaixo do telheiro.

No que se refere ao grau de exposição, como já dissemos, as cartas se situam no espaço privado: Câmara Cascudo escreve para Mário de Andrade e vice-versa. O exemplo 4, a seguir, mostra que as cartas são endereçadas: a Mário de Andrade e a Luis da Câmara Cascudo, que ora se referem apenas a Mário ou Luis, ora a Mário de Andrade, sendo que Luisico, Cascudinho são algumas formas de endereçamento usadas por eles.

Exemplo 4 (identificação dos interlocutores)

Carta de Mário de Andrade a Câmara Cascudo (12/03/1926: 96)

São Paulo, 12 de março de 1926

\section{Luís,}

$[\ldots]$

Carta de Câmara Cascudo a Mário de Andrade (28/04/1926: 102)

Natal, 28 de abril de 1926.

\section{Mário de Andrade.}

$[\ldots]$

Carta de Mário de Andrade a Câmara Cascudo (6/09/1925: 63)

São Paulo, 6 de setembro de 1925. 


\section{Luís do coração,}

[...]

Carta de Câmara Cascudo a Mário de Andrade (13/10/1928: 150)

Recife, 13 de outubro de 1928.

\section{Mário querido.}

$[\ldots]$

Com relação aos focos centrais das cartas que definem os tópicos desenvolvidos, estes são variados, haja vista, por um lado, os interesses de dois renomados escritores brasileiros e, por outro, a amizade que circunscreve esse relacionamento social. Há referências a questões em torno da linguagem, cultura, política, enfim, o que engloba o mundo de dois escritores interessados em arte, literatura, mas também em assuntos do cotidiano familiar, como observamos no último excerto (p. 166) desse exemplo 5.

Exemplo 5 (tópicos das cartas)

[...] Hei de responder primeiro a tudo de você que tenho aqui.

Vamos a ver: Primeiro me diga uma coisa, qual a sílaba tônica de requififi? Palavra aguda ou grave, requifife ou requififi? [...]

(Carta de Mário de Andrade a Câmara Cascudo: 63.)

[...] Seus poemas. Bons. Enérgicos retos. Mas tenho umas observações a fazer. Primeiro que tudo: pelo amor de Deus quando me escrever palavras brasileiras escreva com bastante clareza para eu poder ler certo? [...]

(Carta de Mário de Andrade a Câmara Cascudo: 68.)

[...] Quanto ao Congresso... que tenho eu com ele? As suas ideias ficaram justinhas na minha cabeça. Como se diz por aqui - direito que nem dedo em venta. E os livros... alegrão e leitura vagarosa, mastigada, pautada a refresco de abacaxi, sob árvores. [...] 
(Carta de Luis da Câmara Cascudo a Mário de Andrade: 72.)

[...] sobre a viagem escute: eu terei exames em dezembro e desta complicadíssima forma. Cinco provas escritas e uma oral correspondente a cinco cadeiras. Total de seis dias. Os exames começarão a 3 de dezembro. 8 é dia santo. Somente a 10 ou 11 estarei bacharelando. Falta a colação de grau. Pretendo colar grau em solenidade. [...]

(Carta de Luis da Câmara Cascudo a Mário de Andrade: 152.)

[...] Sua carta chegou aqui numa minha moléstia de rins. Li-a diante da tribo reunida e foi um sucesso. Mamãe remete umas linhas. Papai abraça-o. Eu mando um beijo. Minha mulher e Cotinha enviam lembrançonas. Ariti e Jiguê continuam ótimos, Especialmente Jiguê que é imponente. Ganhei mais dois cães. Um tenerife Bob. Uma policial inglesa, Soviet. [...] (Carta de Luis da Câmara Cascudo a Mário de Andrade: 166)

No que se refere às sequências que configuram as cartas, o excerto 6 exemplifica o que é identificado na maioria delas: local e data, endereçamento, abertura, desenvolvimento, fechamento e assinatura; já o elemento alternativo, o post scriptum é observado em algumas das cartas, podendo ou não ser explicitado.

Exemplo 6

Endereçamento

Mário.

Abertura

Recebi sua carta-bilhete de 19 de dezembro. Carta bem triste e lógica mas demasiado curta para minha ansiedade.

Desenvolvimento

Não há alteração possível para que não compreenda seu coração cheio de sangue e revolta. Tudo quanto em mim existe de claro e de humano, 
de raciocínio e de razão, grita solidariedade antecipada à veemência de sua acusação. Você nada precisa dizer, informar sobre o cerco contra São Paulo, forma única de asfixiar o pensamento da lei n'alma brasileira. [...] E todos nós, seus amigos daqui, continuamos dignos de você. Temos umas duas deserções dolorosas mas só pessoalmente direi. [...]

Fechamento

Fico esperando. Ciao. Bênção ao Nando.

Assinatura

Luís

Data

4 de janeiro de 1933.

Post scriptum

Estou veraneando na praia de Areia Preta. Todos mandam lembranças. Veja se me pode mandar uma medalha paulista do movimento constitucionalista.

Após observarmos a constituição das cartas do ponto de vista genérico, identificamos quais os papéis comunicativos e a posição social dos participantes em jogo no evento. Isso implica considerar a relação social que se estabelece, o status de participação, o relacionamento interpessoal, a natureza dos conhecimentos partilhados e a avaliação que as pessoas realizam.

No tocante à relação entre os interlocutores, observamos que estes cultivam a amizade, conforme identificamos ao longo das cartas, nas diferentes seções que são constitutivas. Os dois autores das cartas se reconhecem enquanto amigos, por isso usam a forma de tratamento "você", própria da intimidade, alcançando o nível da amizade sincera. Consequentemente, são utilizadas diferentes formas de tratamento, sugestivas de proximidade em nossa cultura, para explicitar essa amizade, de acordo com o que sistematizamos a seguir: 


\section{Exemplo 7}

camaradão amigo (p. 75),

meu amigo (p.83),

amigo certo (p. 91),

Luisico (p.122),

Cascudinho do coração (p.132),

Cascudinho (p. 137),

amigão (p. 139),

Luis querido (p. 141),

Querido amigo (p. 149),

Mário querido (p.152),

Mano Mário (159),

bestão querido (172),

Mário do coração natalense (p. 180),

Compadre Mário (p. 229),

Compadre Cascudo (p.230)

Os dados em análise (exemplo 8) evidenciam que os dois interlocutores partilham conhecimentos e crenças, projetos de vidas. Repare-se na forma como desenvolvem o assunto: "carta gentilíssima do Soto" e "artigo sobre a escrava". Isso significa dizer que o conhecimento partilhado dispensa explicações a respeito de quem seja "Soto" e a forma como se refere à obra A escrava que não é Isaura. Assim, desenha-se uma relação simétrica, de identificação e equilíbrio do ponto de vista hierárquico, no espaço construído entre eles. Esse excerto revela a natureza do conhecimento partilhado por Mário de Andrade e Luís da Câmara Cascudo, a realidade comum aos dois interlocutores nesse evento de trocas comunicativas e a instauração do espaço privado. Esse conhecimento é pautado nas afinidades intelectuais e pessoais de dois escritores que juntos comentam, refletem e indagam acerca de questões de interesse literário e cultural, além de expressarem o sentimento da amizade. 


\section{Exemplo 8}

Carta de Mário de Andrade a Luís da Câmara Cascudo (p.82)

Ano-Bom de 1926

Luís,

Deus te dê ano bom. Afinal vou responder à última carta de você. Vou passando bem e a vontade de trabalhar propicia outra vez. Começo por carta aos amigos. A última carta de você importante grande amiga duma vez, me encheu. Merece comentários. Porém antes que me esqueça te conto que recebi anteontem uma carta gentilíssima do Soto com o artigo sobre a escrava saído em Renovación. Deus lhe pague o que você vem fazendo por mim. Vou esperar mais uns cinco ou seis dias pra responder pro Soto, porque assim posso mandar para ele o meu livro novo que sai-não-sai. Você já sabe qual é, o Losango cáqui, versos líricos, coisa íntima, coisa de coração moderno. [...]

Me escreva como quiser, lápis pena máquina, contanto que venha sempre escritura de você. Com paciência e esperteza chego a adivinhar os gatafunhos de você.

Ciao.

Fica pra outro dia a questão religiosa. É assunto por demais importante, o mais importante incontestável da vida, pra ser tratado num dia como o de hoje em que estou com mentalidade de farra.

Me abrace.

Mário.

Conforme discutimos, a construção da amizade entre esses dois escritores brasileiros é identificada na interação, no envolvimento que se estabelece entre eles, e evidenciada nos recursos linguísticos e discursivos presentes nas cartas.

Considerando que o gênero carta pessoal propicia que a confiança existente entre os interlocutores seja passível de identificação, tendo em vista o espaço da escritura que possibilita a construção e manutenção das relações sociais, enumeramos alguns critérios de análise de pontos de vista teóricos aqui discutidos, entre estes: a identificação de enunciados que evidenciam a amizade, 
confiança, a igualdade, na prática da sociabilidade, de acordo com Rezende (2002) e Oliveira (2009); identificação de léxico específico cujo significado é reconhecido pelos interlocutores, no sentido de pertença e afiliação; enunciados que materializam a conexão interna emocional, conforme Tannen (2007); enunciados que explicitam o envolvimento com ou outro (Chafe, 1982 e 1985).

A seguir, analisamos fragmentos das cartas que revelam a amizade patente entre Mário de Andrade e Câmara Cascudo e o vínculo do afeto tecido entre eles.

\subsection{Marcas da amizade}

No excerto 9, Luis da Câmara Cascudo se refere a Mário de Andrade como "meu caro amigo" (linha 1) e expressa seu afeto na forma de "amo voce" (linha 3). Observamos, também, que o envolvimento interpessoal é explicitado por meio de léxico indicativo de reciprocidade entre um autor e o outro, meu+amigo e amo+você.

\section{Exemplo 9}

Carta de Luís da Câmara Cascudo a Mário de Andrade (25-08-1924: 35)

[...] Aqui estou às suas ordens, meu caro amigo. Muito me julgarei honrado merecendo uma ordem sua. $\mathrm{Na}$ falta de ordem mande um retrato. Desejava dá-lo numa revista aqui do Norte. Eu sou "presentista". Amo a você (sentido figurado), detesto os seus imitadores. [...]

No exemplo 10, "o desejo sincero de o conbecer" é compreendido como a confiança que Mário de Andrade postula que se estabeleça entre ele e o interlocutor Câmara Cascudo. Não é apenas o desejo, mas a forma intensificada no adjetivo "sincero". Igualmente ao exemplo anterior, a seleção lexical propicia a compreensão do envolvimento entre quem escreve e o seu endereçado.

Exemplo 10

Carta de Mário de Andrade a Luis da Câmara Cascudo (26-09-1924: 39)

[...] Aqui vai o meu sincero desejo de o conhecer pessoalmente. [...] 
O fragmento 11 ressalta a escolha lexical realizada por Cascudo para categorizar a carta anterior de Andrade - "afetiva" e "efetiva"- e a "alegria" que a escritura propicia. Esse sentimento o faz evocar o nome do amigo e repeti-lo nessa interação que é propiciada.

\section{Exemplo 11}

Carta de Luís da Câmara Cascudo a Mário de Andrade (19-05-1925: 40)

[...] E sua carta afetiva (e efetiva) encheu-me de alegria. Creia que repito aqui seu nome e sua ação. [...]

Ao declarar o desejo de obter algo (foto, desenho, traço, etc.) que possa personificar (dar o jeitão) o amigo, Cascudo demonstra a necessidade de criação do espaço da amizade, do bem-querer, como identificamos no exemplo 12. Esse enunciado torna clara a identificação entre os interlocutores, podendo-se vislumbrar o sentimento de pertença na relação de amizade. Essa questão é também observada no uso abreviado do pronome você (v.), manifestação reveladora de envolvimento com o outro.

\section{Exemplo 12}

Carta de Luís da Câmara Cascudo a Mário de Andrade (19-05-1925: 40)

[...] Volto a insistir no desejo de ter um retrato, um desenho, uma caricatura, uns traços, umas rabiscas, algo que me dê o jeitão de Mário. V. já escreveu que a bondade era a virtude mais solar.

O uso de linguagem comum, compreendida como marca de envolvimento interpessoal, é observado no enunciado do exemplo 13. Nesse sentido, o mesmo sentimento afetivo transcende nas horas de conversa com quem se quer bem, conforme menciona Cascudo em relação ao interlocutor Mário. Observamos, também, a conexão interna do autor, na referência ao enunciado "encho minhas horas", que expressam o ego-envolvimento, porém, direcionadas ao contato com o interlocutor, no caso, a “quem”, ele devota afeição. 


\section{Exemplo 13}

Carta de Luís da Câmara Cascudo a Mário de Andrade (22-08-1925: 55)

Estou ainda agarrado à gripe. Ora aí está porque encho as minhas horas conversando com quem quero bem. Reli sua carta última.

A questão mais específica do envolvimento com o outro, ressaltando um vocabulário indicativo da amizade que cerca os dois escritores brasileiros é identificado nas cartas cujos excertos comentamos a seguir. No exemplo 14, Mário de Andrade se utiliza do pronome "você", para dizer o quanto o outro "é bom" para ele e quanto cada carta dignifica "um carinho de você". Há, no discurso aqui analisado, nitidamente, um direcionamento ao outro, sob uma forma que consideramos casual, simétrica.

Exemplo 14

Carta de Mário de Andrade a Luís da Câmara Cascudo (22-08-1925: 63)

[...] Como você é tão bom para mim! Cada carta de você é um carinho descansante para mim, fico feliz. Deus lhe pague. [...]

No exemplo 15 também identificamos que a identidade, a afinidade entre Cascudo e Mário de Andrade se reflete nas formas como eles se referem um ao outro, as quais indicam o envolvimento interacional entre eles. Podemos então mencionar que Cascudo aparece, no dizer de Mário de Andrade, como: "Camaradão amigo", "você", "Luis", "amigo", além de salientar "nossa amizade" e ressaltar a identificação existente entre eles caracterizada na "vida uma só de dois iguais".

\section{Exemplo 15}

Carta de Mário de Andrade a Luís da Câmara Cascudo (26-11-1925: 75-76)

Luis, eu sou tão feliz! Puxa! que camaradão amigo mesmo de verdade eu arranjei dentro de você...[...]

$\mathrm{Na}$ nossa amizade, Luís, me parece que já passamos o tempo do aperto de mão e do "você" apenas... Já estamos no período mais amigo 
em que a gente pode passar dez minutos um ao lado do outro, sem falar, sem procurar assunto, vivendo apenas a vida uma só de dois iguais e bem se conhecendo: É doce viver a existência do amigo.

Essas ocorrências que identificam o "nós" situado nas cartas aparecem, sobretudo, nas conexões por meio dos pronomes "você" (v.) e "minha", "me", "de você", conforme exemplos 16 e 17, compreendidos no contexto da grande amizade que os interlocutores.

Exemplo 16

Carta de Mário de Andrade a Luís da Câmara Cascudo (01-1926: 86)

[...] Me escreva como quiser, lápis pena máquina, contanto que venha sempre escritura de você. Com paciência e esperteza chego a adivinhar os gatafunhos de você. [...]

Exemplo 17

Carta de Luís da Câmara Cascudo a Mário de Andrade (09-03-1926: 94)

[...] Remeto um livreco meu. O primeiro. Não leia. Registe e mande um abraço pela minha grande prova de amizade.

Assim, observamos que as cartas trocadas entre Câmara Cascudo e Mário de Andrade evidenciam o gênero usado pelos interlocutores com finalidades que emergem em cada contato, entre estas o estabelecimento da relação social entre dois interlocutores que se tornam amigos. Eles falam de política, opinam sobre cultura, literatura, ressaltam preocupações diante das ocorrências da vida diária e, mantêm a relação de amizade à distância na maior parte do tempo.

\section{CONSIDERAÇÕES FINAIS}

As reflexões deste trabalho possibilitaram tecer algumas considerações, com base nas ocorrências analisadas. Do ponto de vista genérico, cartas pessoais se concretizam em uma determinada esfera de comunicação, com objetivos que podem ser variados, até sobrepostos, já que os interlocutores 
trocam correspondências, se estabelecendo no espaço privado como amigos, parentes, pais, irmãos, entre outros. No caso deste estudo, especificamente, as cartas foram utilizadas com objetivos diferenciados, entre estes: para contar ocorrências da vida cotidiana, para reclamar de ausências de pessoas, para trocar opiniões acerca de questões de interesses comuns, enfim, atender a cada uma das vontades e desejos daqueles que se utilizaram do gênero.

Identificamos, nesta investigação, que as cartas se configuram estabelecendo o tempo, o espaço, o tratamento direcionado ao outro, a abertura da interlocução, o desenvolvimento, a finalização, o post scriptum, haja vista as características das formas epistolares mantidas ao longo do tempo. No entanto, as escolhas lexicais - o que implica o modo de dizer, os pontos de vista veiculados fazem parte da relação interativa com o outro, que aparece nas formas de "querido amigo", "te abraco", "Meu amigo", "escreva pelo amor de Deus". Tais ocorrências deixam transparecer, muitas vezes, uma interação próxima ao que se observa em situações face a face.

Compreendemos, assim, que a escritura e também a leitura de cartas pessoais caracterizam-se enquanto formas específicas de interação, instauradas quando cada interlocutor evoca a presença do outro, objetivando construir um diálogo na ausência. Essa interação é mediada por trocas comunicativas, de sociabilidade, nesses textos escritos, tornando-se evidentes os conhecimentos partilhados, que colocam em relevo questões no âmbito da cultura, da literatura, da política, da família, da amizade. Esses conhecimentos comuns aos dois escritores são visíveis nas questões inferidas nas cartas, sem que sejam necessárias maiores explicações deles relacionadas a pessoas, fatos e situações específicas.

Nessa direção, as cartas que se desenvolvem por meio de tópicos discursivos revelam centração em referentes da vida pessoal e da vida social circundante, das experiências vividas em espaços distantes e próximos a cada um destes interlocutores. Assim, identificamos a relação subjetiva de amizade, fundada na confiança, em um grau considerável de proximidade construída na ausência, criando efeitos de sentido que materializam os modos de vida dos dois escritores. Nessa direção, ressalta-se o grau de relação de poder e cumplicidade, de expressividade, caracterizado como horizontal, no sentido proposto por Brandão, Andrade e Aquino (2009). 
Assim, observamos que o envolvimento interacional entre os escritores se manifesta linguística e discursivamente nas formas de tratamento indicativas do grau de proximidade entre eles, da simetria de um contrato social entre amigos, compadres, escritores representativos da era moderna brasileira. É evidente o envolvimento no discurso nas escolhas de enunciados, compreendidos como evidências da amizade que é iniciada e consolidada, conforme transparece nas interlocuções, nas formas de meu amigo, amigo certo, querido amigo, mano.

Por fim, entendemos que a subjetividade patente nas cartas pessoais possibilita a compreensão do lugar de negociação das relações sociais entre as pessoas, no conjunto de atos pragmáticos, deixando entrever de quem, para quem, quando e quais os propósitos comunicativos em determinado contexto, de acordo com o que postula Rezende (2002) em sua visão acerca da antropologia das emoções.

\section{BIBLIOGRAFIA}

ALLAN, Graham. 1989. Friendship: developing a sociological perspective. Boulder/ San Francisco: Westview Press.

ALLWOOD, J. 1976. Linguistic comunication as action and cooperation, a study in pragmatics. Tese de doutorado. Goeteborg: Universidade de Goetborg.

ANDRADE, M. L. da C. V. 2010. A intimidade da ausência: estudo de marca de oralidade em cartas pessoais do século XIX. In. PRETI, D. (org). Oralidade em textos escritos. Projetos Paralelos - NURC/SP. São Paulo: Humanitas, p. 189-216.

BAKHTIN, M. 2000. Estética da criação verbal. São Paulo: Martins Fontes.

BAZERMAN, C. Gêneros textuais, tipificação e interação. In. DIONÍSIO, A. HOFFNAGEL, J. C. (orgs.), São Paulo: Cortez, 2005.

BIBER, Douglas. Variation across speech and writing. Cambridge: Cambridge University press, 1988.

BRANDÃO, H. N.; ANDRADE, Maria Lúcia C. V. O.; AQUINO, Zilda G. O. 2009. Cartas da administração privada publica e cartas particulares: estudo da organização discursiva. In. VANDERCI, A.(org). Para a bistória do português brasileiro. Volume VII: vozes veredas, voragens. Tomo II. Londrina: EDUEL, 2009, p. 699-737.

CASCUDO, L. da C. ANDRADE, M. de. Cartas, 1924-1944. São Paulo: Global, 2010. 
CHAFE, W. 1984. Integration and involvement in speaking, writing, and oral literature. In. TANNEN, D. (ed.) Spoken and written language: exploring orality and literacy. Norwood: 1982, p. 35-53.

. Integration and involvement in spoken and written language. In. BORBE, T. (ed). Semiotics unfolding. Berlin: Mouton, p. 1095-1102.

1985. Linguistics differences produced by differences between speaking and writing. In. OLSON, D; TORRANCE, N; HILDYARD, A. Literacy, language and learning: the nature and consequences of reading and writing. Cambridge: Cambridge University Press, p. 105-123.

EGGINS, S; SLADE, D. Analysing casual conversation. London: Cassell, 1997.

FÁVERO, L. L; JUBRAN, C. C. A. S; HILGERT, J. G; BARROS, K. S. M. de; TOSCANO, M. E. S; ANDRADE, M. L. C. V; CRESCITELLI, M. F. C; GALEMBECK, P. de T; AQUINO, Z. G. O. de. Interação em diferentes contextos. In. BENTES, A. C; LEITE, M. Q. (orgs). Linguística de texto e análise da conversação: panorama das pesquisas no Brasil. São Paulo: Cortez, 2010, p 91-158.

GOFFMAN, E. Les rites d'interaction. Paris: Les Éditions de Minuit, 1974.

GUMPERZ, J. 1982. Discourse strategies. Cambridge: Cambridge University Press, 1982.

GUMPERZ, J; HYMES, Dell. (Eds). Directions in sociolinguistics: the ethnography of communication. New York: Holt, Reinehart and Winston, 1974.

HENNE, H.; REHBOCK, H. Einfübrung die Gesprächsanalyse. Berlin: de Gruyter, 1982. KERBRAT-ORECCHIONI, K. Análise da conversação: princípios e métodos. Tradução de Carlos Piovezani Filho. São Paulo: Parábola, 2006.

MORATO, E. O Interacionismo no campo linguístico. In. MUSSALIN, F.; BENTES, A. C. (orgs). Introdução à linguística: fundamentos epistemológicos. São Paulo: Cortez, vol. 3, 2004, 311-352.

MARCUSHI, L. A. Perspectivas dos estudos de interação social da lingüística brasileira dos anos 90. Conferência apresentada na SBPC do Maranhão - UFMA, São Luiz: UFMA, 1998.

Parábola, 2008.

MARCUSCHI, L. A. Produção textual, análise de gêneros e compreensão. São Paulo:

OLIVEIRA, L. Da amizade como exercício das virtudes. In. Hypnos, número 22, $1^{\circ}$ Semestre, São Paulo, 2009, p. 129-140.

PAINE, Robert. 1974. An exploratory analysis of 'middle-class' culture. In: LEYTON, E. (org.), The Compact. selected dimensions of friendship. Newfoundland: Memorial University of Newfoundland,

REZENDE, C. B. Mágoas de amizade: um ensaio em antropologia das emoções. MANA 8(2): 2002, p. 69-89. 
SÊNECA, L. A. Ad Lucilium epistulae morales. 3 v. With english translation by Richard Gummere. Cambridge: Harvard University Press, 1989.

SUTTLES, Gerald D. Friendship as a social institution. In. Mc-CALL G. J. et ali (orgs.), Social relationships. Chicago: Aldine Publishing Company, 1970.

SILVA, V. L. P. da. Variações tipológicas no gênero textual carta. In. KOCH, I. V; BARROS, K. S. M. de. Tópicos em linguística de texto e análise da conversação. Natal: EDUFRN, 1997, p. 118-124.

SILVA, J. Q. G. Um estudo sobre o gênero carta pessoal: das práticas comunicativas aos indícios de interatividade na escrita dos textos. Tese de Doutorado, Belo Horizonte: UFMG, 2002.

SIMÕES, J. 2007. Sintaticização, discursivização e semanticização das orações de gerúndio no português brasileiro, Tese de Doutorado, Universidade de São Paulo, São Paulo-SP.

SIMÕES, J; KEWITZ, V. Tradições discursivas e organização de corpora. In. AGUILERA, V. (org.). Para a história do português brasileiro. Volume VII: vozes veredas, voragens. Tomo II. Londrina: EDUEL, 2009, p. 467-529.

TANNEN, D. Talking voices: repetition, dialogue, and imagery in conversational discourse. Cambridge: Cambridge University Press, 2007.

TANNEN, D. Relative focus on involvement in oral and written discourse. In. OLSON, D; TORRANCE, N; HILDYARD, A. (ed). Literacy, language and learning: the nature and consequences of reading and writing. Cambrige: Cambridge University Press, 1985, p. 124-147.

VION, R. La communication verbale: analyse des interactions. Paris: Hachete Supérior, 1992.

\title{
Notes on friendship: a study on interactional involvement in personal letters
}

\begin{abstract}
The main focus of this work is the description and analysis of aspects of verbal interaction in personal letters, the central corpus of the investigation consisting of correspondence between Mário de Andrade and Luís Câmara Cascudo. It begins with a discussion of genre, as an empirical entity, followed by reflections on the personal letter as a genre realized in human interactions. In this context, among the various identifiable goals for writing letters, the possibility of the interlocutors maintaining friendship is salient, even when parties are at great distances from one another, measured by the involvement installed between them. Thus, having interactive postulados as a base, this research proposes an interpretative and inductive analysis, of linguistic and discursive phenomenon evidenced in the personal letters selected.
\end{abstract}

Keywords: personal letters, verbal interaction, involvement 